\title{
SPECTROSCOPIC PROPERTIES OF NEODYMIUM PERCHLORATES IN 2-HALOGENO DERIVATIVES OF ETHANOL. PART II
}

\author{
B. KeLler AND J. LEgendziEWiCZ \\ Institute of Chemistry, University of Wroclaw \\ F. Joliot-Curie 14, 50-383 Wrocław, Poland
}

\begin{abstract}
The spectroscopic studies of anhydrous neodymium perchlorate in two series of 2-halogeno derivatives of ethyl alcohol are presented. The changes of intensities of ${ }^{4} I_{9 / 2} \rightarrow{ }^{2} G_{7 / 2},{ }^{4} G_{5 / 2}$ hypersensitive transitions are discussed within the framework of Mason's polarizability mechanism. Anomalous dependence of band intensities was found for the 2-fluoro derivatives. The linear relation of oscillator strength vs. solvent polarizability was broken for the 2-bromine and 2-iodine derivatives of ethyl alcohol. The effort was made for explanation of such strange results.
\end{abstract}

PACS numbers: $78.20 . \mathrm{Wc}, 78.55 . \mathrm{Hx}$

\section{Introduction}

Recently the spectroscopic results for neodymium anhydrous perchlorate in 2-chlorine derivatives of ethyl alcohol were reported [1]. It was found that the polarizability mechanism plays an important role in the radiative transition intensities and affects mainly the transitions for which the selection rule is $|\Delta J| \leq 2$. This effect can be easily observed when the structural factors of investigated samples are the same [2].

In this paper we extend our spectroscopic investigation over the two other series of 2-halogeno ethyl alcohol derivatives. For the former, the molar refractivity is almost constant and for the second one it changes significantly. The investigation were undertaken in aim to confirm the previous relation.

\section{Experimental}

Experimental details can be found in [1]. 


\section{Results and discussion}

In the course of our studies of the polarizability effect on the intensities of hypersensitive transition we have undertaken spectroscopic studies of the neodymium perchlorate in two series of 2-halogeno derivatives of ethyl alcohol:

(1) $\mathrm{CH}_{3} \mathrm{CH}_{2} \mathrm{OH}, \mathrm{CH}_{2} \mathrm{FCH}_{2} \mathrm{OH}, \mathrm{CF}_{3} \mathrm{CH}_{2} \mathrm{OH}$

and

(2) $\mathrm{CH}_{2} \mathrm{FCH}_{2} \mathrm{OH}, \mathrm{CH}_{2} \mathrm{ClCH}_{2} \mathrm{OH}, \mathrm{CH}_{2} \mathrm{BrCH}_{2} \mathrm{OH}, \mathrm{CH}_{2} \mathrm{ICH}_{2} \mathrm{OH}$.

In Table I the oscillator strength values of $f-f$ transition in anhydrous neodymium perchlorate solution spectra at room temperature are listed. Anomalous change of oscillator strengths can be read for the first series of alcohols $\left(\mathrm{CH}_{3} \mathrm{CH}_{2} \mathrm{OH}\right.$,

TABLE I

The oscillator strength values $P$ for $\mathrm{Nd}\left(\mathrm{ClO}_{4}\right)_{3}$ in ethanol and its 2-halogeno derivatives.

\begin{tabular}{|c|c|c|c|}
\hline Term & $\begin{array}{c}\mathrm{CH}_{3} \mathrm{CH}_{2} \mathrm{OH} \\
P \times 10^{8}\end{array}$ & $\begin{array}{c}\mathrm{CH}_{2} \mathrm{FCH}_{2} \mathrm{OH} \\
P \times 10^{8}\end{array}$ & $\begin{array}{c}\mathrm{CH}_{2} \mathrm{ClCH}_{2} \mathrm{OH} \\
P \times 10^{8}\end{array}$ \\
\hline${ }^{4} F_{3 / 2}$ & 254.03 & 245.68 & 240.97 \\
\hline${ }^{4} F_{5 / 2},{ }^{2} H_{9 / 2}$ & 903.55 & 845.25 & 824.31 \\
\hline${ }^{4} F_{7 / 2},{ }^{4} S_{3 / 2}$ & 883.75 & 854.93 & 798.56 \\
\hline${ }^{4} F_{9 / 2}$ & 54.89 & 54.60 & 53.23 \\
\hline${ }^{2} H_{11 / 2}$ & 14.10 & 13.91 & 11.55 \\
\hline${ }^{4} G_{5 / 2},{ }^{2} G_{7 / 2}$ & 1014.83 & 1199.35 & 1638.00 \\
\hline $\begin{array}{l}{ }^{2} K_{13 / 2},{ }^{4} G_{7 / 2}, \\
{ }^{4} G_{9 / 2}\end{array}$ & 612.72 & 652.66 & 667.21 \\
\hline $\begin{array}{l}{ }^{2} K_{15 / 2},{ }^{2} G_{9 / 2} \\
\left({ }^{2} D,{ }^{2} F\right)_{3 / 2},{ }^{4} G_{11 / 2}\end{array}$ & 160.53 & 162.06 & 160.16 \\
\hline${ }^{2} P_{1 / 2},{ }^{2} D_{5 / 2}$ & 43.96 & 44.95 & 36.28 \\
\hline $\begin{array}{l}{ }^{4} D_{3 / 2},{ }^{4} D_{5 / 2} ;{ }^{2} I_{11 / 2} \\
{ }^{4} D_{1 / 2},{ }^{2} L_{15 / 2}\end{array}$ & 885.80 & 939.97 & 996.71 \\
\hline Term & $\begin{array}{c}\mathrm{CH}_{2} \mathrm{BrCH}_{2} \mathrm{OH} \\
P \times 10^{8}\end{array}$ & $\begin{array}{c}\mathrm{CH}_{2} \mathrm{ICH}_{2} \mathrm{OH} \\
P \times 10^{8}\end{array}$ & $\begin{array}{c}\mathrm{CF}_{3} \mathrm{CH}_{2} \mathrm{OH} \\
P \times 10^{8}\end{array}$ \\
\hline${ }^{4} F_{3 / 2}$ & 317.98 & 262.87 & 218.69 \\
\hline${ }^{4} F_{5 / 2},{ }^{2} H_{9 / 2}$ & 871.92 & 885.88 & 732.27 \\
\hline${ }^{4} F_{7 / 2},{ }^{4} S_{3 / 2}$ & 903.92 & 871.09 & 716.20 \\
\hline${ }^{4} F_{9 / 2}$ & 55.47 & 58.03 & 50.51 \\
\hline${ }^{2} H_{11 / 2}$ & 13.51 & 15.99 & 11.71 \\
\hline${ }^{4} G_{5 / 2},{ }^{2} G_{7 / 2}$ & 1020.23 & 1580.13 & 1809.26 \\
\hline $\begin{array}{l}{ }^{2} K_{13 / 2},{ }^{4} G_{7 / 2} \\
{ }^{4} G_{9 / 2}\end{array}$ & 684.95 & 708.03 & 661.38 \\
\hline $\begin{array}{l}{ }^{2} K_{15 / 2},{ }^{2} G_{9 / 2} \\
\left({ }^{2} D,{ }^{2} F\right)_{3 / 2},{ }^{4} G_{11 / 2}\end{array}$ & 170.69 & 165.55 & 151.24 \\
\hline${ }^{2} P_{1 / 2},{ }^{2} D_{5 / 2}$ & 43.48 & 49.50 & 54.00 \\
\hline $\begin{array}{l}{ }^{4} D_{3 / 2},{ }^{4} D_{5 / 2},{ }^{2} I_{11 / 2} \\
{ }^{4} D_{1 / 2},{ }^{2} L_{15 / 2}\end{array}$ & 1028.24 & 927.73 & 998.42 \\
\hline
\end{tabular}


$\mathrm{CH}_{2} \mathrm{FCH}_{2} \mathrm{OH}$, and $\mathrm{CF}_{3} \mathrm{CH}_{2} \mathrm{OH}$ ) whose molar refractivities are comparable; consequently, in the framework of the Mason theory [3] their intensities should be constant. The intensity of hypersensitive transition increases from ethyl alcohol to $\mathrm{CF}_{3} \mathrm{CH}_{2} \mathrm{OH}$. Such a change in intensities is unexpected and striking. For the second series of alcohols the changes of intensities of hypersensitive transition are observed, but the linear relation is broken.

In our previous studies of spectroscopic properties of lanthanide compounds in nonaqueous solutions the effect of the solvent refractivity on the intensity of hypersensitive transitions was found $[1,2,4]$. We proposed the polarizability mechanism of Mason as a mechanism responsible for the observed linear dependence of the square root of oscillator strength on the solvent refractivity, which explains well the intensity of hypersensitive transitions of lanthanide complexes.

According to the dynamic coupling theory, the oscillator strength of hypersensitive transition in lanthanide complexes may be expressed in the form

$$
\begin{aligned}
P_{a b}=\frac{8 \pi^{2} m c \tau \sigma}{15 h(2 J+1)}\left(1-\sigma_{2}\right)^{2}\left\langle 4 f\left|r^{2}\right| 4 f\right\rangle\left\langle f\left\|c^{(2)}\right\| f\right\rangle \\
\quad \quad \times\left\langle f^{n}\left(M_{a}\right) J\left\|U^{(2)}\right\| f^{n}\left(M_{b}\right) J^{\prime}\right\rangle^{2} \sum_{p} \sum_{q}\left|\sum_{s} T_{-p-q}^{(3)}(s) \bar{\alpha}(s)\right|^{2} .
\end{aligned}
$$

The oscillator strength $P$ is, in a rough approximation, proportional to the square of ligand or solvent polarizability. However, for the series of solvents tested, the linear relation was not valid $[1,5]$. We found a good linear relation of oscillator strength values for the 2-chloro derivatives of ethyl alcohol, for which the structure factors are the same. Unexpected results were obtained for mono- and trifluoro derivatives of ethanol.

Examination of the data compiled in Table I needs analysing of the tendency of 2-fluoro derivatives to form strong hydrogen bondings and to create clathrate structures in solution. Judging from the changes of oscillator strength in 2-trifluoro derivatives, the order of hydrogen bonding strength in solution is well confirmed.

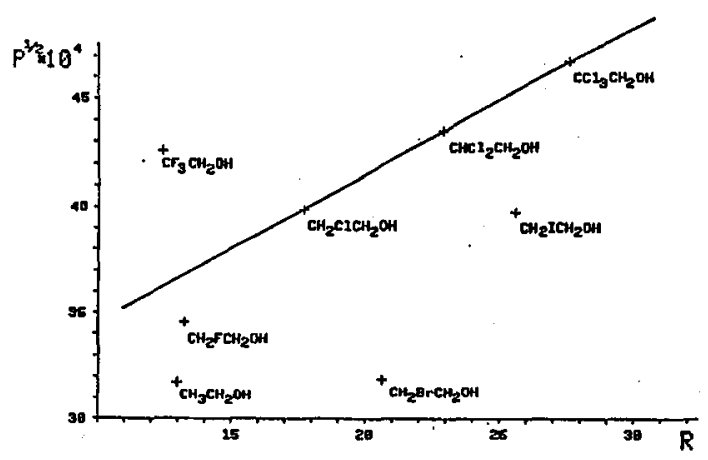

Fig. 1. The dependence of the square root of oscillator strengths of hypersensitive transitions on molar refractivity. 
Consequently, the molar weight included in molar refractivity is higher, leading to a shift of the data in Fig. 1 for $\mathrm{CF}_{3} \mathrm{CH}_{2} \mathrm{OH}$ on the right. The analysis of the intensity changes in the second series of alcohols indicates some non-regularities both in oscillator strength of hypersensitive transition and $\tau_{2}$ parameters values presented in Table II. Such an anomalous variation of oscillator strengths can re-

\section{TABLE II}

The $T_{\lambda}$ parameters for $\mathrm{Nd}\left(\mathrm{ClO}_{4}\right)_{3}$ in ethanol and its 2-halogeno derivatives.

\begin{tabular}{l|c|c|c}
\hline \hline \multicolumn{1}{c|}{ Solvent } & $\tau_{2} \times 10^{9}$ & $\tau_{4} \times 10^{9}$ & $\tau_{6} \times 10^{9}$ \\
\hline $\mathrm{CH}_{3} \mathrm{CH}_{2} \mathrm{OH}$ & $2.12 \pm 0.46$ & $5.42 \pm 0.43$ & $10.40 \pm 0.59$ \\
$\mathrm{CH}_{2} \mathrm{ClCH}_{2} \mathrm{OH}$ & $5.48 \pm 0.41$ & $6.20 \pm 0.38$ & $9.18 \pm 0.52$ \\
$\mathrm{CHCl}_{2} \mathrm{CH}_{2} \mathrm{OH}$ & $7.32 \pm 0.42$ & $5.79 \pm 0.39$ & $8.39 \pm 0.53$ \\
$\mathrm{CCl}_{3} \mathrm{CH}_{2} \mathrm{OH}$ & $8.63 \pm 0.38$ & $6.39 \pm 0.36$ & $9.31 \pm 0.49$ \\
$\mathrm{CF}_{3} \mathrm{CH}_{2} \mathrm{OHI}$ & $6.54 \pm 0.38$ & $6.26 \pm 0.35$ & $8.07 \pm 0.48$ \\
\hline $\mathrm{CH}_{2} \mathrm{FCH}_{2} \mathrm{OH}$ & $3.04 \pm 0.45$ & $5.81 \pm 0.45$ & $9.84 \pm 0.57$ \\
$\mathrm{CH}_{2} \mathrm{ClCH}_{2} \mathrm{OH}$ & $5.48 \pm 0.41$ & $6.20 \pm 0.38$ & $9.18 \pm 0.52$ \\
$\mathrm{CH}_{2} \mathrm{BrCH}_{2} \mathrm{OH}$ & $1.54 \pm 0.54$ & $6.45 \pm 0.49$ & $10.37 \pm 0.67$ \\
$\mathrm{CH}_{2} \mathrm{ICH}_{2} \mathrm{OH}$ & $5.35 \pm 0.54$ & $5.74 \pm 0.50$ & $10.21 \pm 0.67$
\end{tabular}

sult from a change of the structure of solvates or from contribution of additional mechanism in the intensities of hypersensitive transition. The low-temperature investigation can distinguish between these phenomena. In Fig. 2 there are presented absorption spectra of solid solutions at 5 and $293 \mathrm{~K}$ of 2-bromo and 2-iodo derivatives of alcohol. One can find the broadening of bands, indicating thus a pseudo-disordered structure of solution. Analysis of optical lines of hypersensitive and ${ }^{4} I_{9 / 2} \rightarrow{ }^{2} P_{1 / 2}$ transitions of both systems under investigation leads to following conclusion: in the former - one form of solvates is created with disordered like glass structure, in the latter - two different forms of solvates exist with probably different symmetry distortion. The shift of the energy of ${ }^{2} P_{1 / 2}$ transition from one system to another indicates a difference in the splitting patterns of the two systems. On the other hand, the fine structure of weak components of ${ }^{4} F_{5 / 2},{ }^{2} H_{9 / 2}$ transition at $5 \mathrm{~K}$ confirms the electron-phonon coupling and creation of vibronic sidebands in electronic transition. These two effects can explain the anomalous variation of oscillator strength disturbing the linear relation of oscillator strengths vs. polarizability of solvent molecules.

The investigation of temperature dependence of intensities from 293 to $5 \mathrm{~K}$ can provide additional arguments for the electron-phonon coupling in the system studied. It will be the aim of our further investigation. 


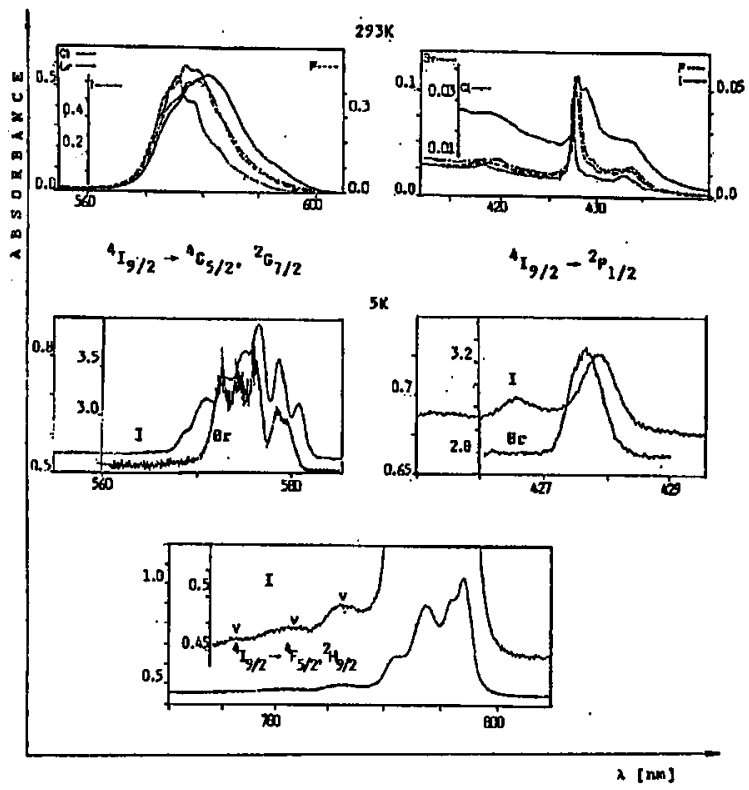

Fig. 2. The absorption spectra of $\mathrm{Nd}_{(}\left(\mathrm{ClO}_{4}\right)_{3}$ in ethanol 2-halogeno derivatives at $293 \mathrm{~K}$ and $5 \mathrm{~K}$.

\section{References}

[1] B. Keller, J. Legendziewicz, G. Oczko, in: Excited State of Transition Elements, Eds. B. Jeżowska-Trzebiatowska, J. Legendziewicz, W. Stręk, World Sci., Singapore 1992, p. 354.

[2] G. Oczko, J. Legendziewicz, B. Keller, B. Jeżowska-Trzebiatowska, Spectrochim. Acta A 45, 945 (1989).

[3] S.F. Mason, R.D. Peacock, B. Steward, Mol. Phys. 30, 1829 (1975).

[4] J. Legendziewicz, B. Keller, W. Stręk, Chem. Phys. Lett. 92, 205 (1982).

[5] J. Legendziewicz, G. Oczko, B. Keller, W. Stręk, B. Trzebiatowska, J. Mol. Struct. 115, 421 (1989). 